\title{
Leprosy care through traditional healers
}

\author{
PARAMJIT KAUR, U C SHARMA, S S PANDEY \\ \& SINGH GURMOHAN \\ Institute of Medical Sciences, Banaras Hindu University, \\ VARANASI-221005
}

Accepted for publication 16 June 1983

Summary An encouraging increase in the knowledge of leprosy has been found in traditional healers after training has been given. Evaluation was by pre- and post-training questionnaires to which scores were assigned. Their role in leprosy care at the community level is also being discussed.

The traditional healer is part and parcel of the social milieu where he commands respect and has an intimate relationship with his clientele. Considering the present manpower in the National Leprosy Control Programme we can think of this alternative approach as a boost. In addition, the negative aspects of health care as practised by many practitioners can also be corrected by the appropriate training.

\section{Introduction}

Leprosy has been given top priority in our National Programme, and by AD 2000 the Government of India hopes to eradicate leprosy.

Our grassroot level worker is a non-medical assistant who perhaps is not acceptable to the community because people have great faith in a large number of other health providers, most of whom are traditional healers. A traditional healer is any practitioner not institutionally qualified but practising any system of medicine, folk medicine and or magico-religious practices in the same sociocultural setting as the clientele. We have been working with the traditional healers for quite some time in this area.

The present study was conducted to find out if the traditional healers are interested in acquiring modern knowledge of leprosy and other skin diseases and to see if additional training could improve the standard of their health provision. 


\section{Materials and methods}

A training programme of the traditional healers was taken up in the village Narainpur of Chiraigaon block of the Varanasi District, population 2000.

A list of traditional healers working in the area was made. Out of 122 practitioners working in the area, 20 were selected for training by using the following criteria. (1) Skin practitioners who are involved in healing skin diseases and are willing to undergo training. (2) Willing practitioners with sufficient learning capacity. (3) Those with a large client record. (4) Those practitioners with a larger catchment area. (5) Level of interest for undergoing the training.

Along with leprosy some other common skin diseases, namely, scabies, ringworm (dermatophytoses), eczema, vitiligo, pyodermas (impetigo and furunculosis) and urticaria were also taught to the trainees.

The knowledge and practice of the trainees regarding the above conditions were assessed with the help of a predesigned and pretested proforma. The same proforma was also used for post-training assessment.

The training was given on 5 consecutive days. The programme was arranged to suit the convenience of the trainees. The training material included a manual in the regional language (Hindi), photos and slides of the cases, clinical demonstration of the patients and the drugs used for treatment.

Knowledge about the causation, mode of transmission, the cardinal signs and curability of leprosy was given. The trainees were particularly told about the misconceptions prevalent in the community regarding leprosy. They were also told that dapsone is the treatment of choice and has to be continued for long periods. They were taught that the patients with any one of the cardinal signs of leprosy should be referred to the nearest leprosy clinic. They were, however, not advised to stop any other treatment that they have been practising. The post-training assessment was done by following the practitioners 1 week after the training and then at monthly intervals for 3 occasions. Retraining at individual level was also done during this follow-up period. Some patients under the treatment of trainees were also cross-checked to assess the post-training practice.

The knowledge of the practitioners before and after training was scored by giving points according to the importance of the messages, and half of the actual score was allocated to the answers given after probing. A leprosy pretesting questionnaire carried 32 points. Only those questions which carried positive scores are listed below, others are omitted.

\section{Results}

Out of the 20 practitioners, $15(75 \%)$ were literate and $5(25 \%)$ were illiterate and $80 \%$ of the practitioners were male while $20 \%$ were females. 


\section{Questionnaire}

1 How do you recognize leprosy?

Scores assigned

i Hypopigmented patches without itching. 2

ii No pain sensation over the patch. 2

iii Loss of hair over the patch. 1

iv Loss of sensation of hands and feet.

$v$ Loss of eyebrows. 1

vi Thickening of ear. 1

vii Depressed nose. 1

viii Deformities of hands and feet. 1

2 What is the cause of leprosy?

i By a germ. 2

3 Does it spread? Yes; If yes, how does it spread? 2

i By close contact. 2

4 Can the spread of the disease be prevented? Yes, If yes, how?

i Early treatment of the patient. 2

ii Avoid contact with the patient when he is infective. 1

5 What is the treatment?

i Name of the medicine-dapsone. 3

ii Dose of the medicine- $100 \mathrm{mg}$ daily. 2

iii Duration of treatment -5 or more years. 2

6 When should you refer a case to a doctor?
i After diagnosis.

ii Suspected cases. 1

iii After 5 years of treatment. 1

7 To whom should you refer the case: RHC/Doctor/Chiraigaon PHC/Ashapur Leprosy Hospital or others (specify). One score each for any two places only.

The age of the trainees varied from 22 to 72 years. Most of the practitioners $(45 \%)$ were in the age group of $22-34$ years followed by $35 \%$ in the age group of 45 years and above, while $20 \%$ were in the age range of 35-44 years (Table 1 ).

Out of the maximum possible score of 32, the pre-training score of practitioners varied from $2 \cdot 0$ to 16.0 with a mean $7 \cdot 2 \pm 4 \cdot 1$, which was $22.5 \%$ (Table 2). After training the mean score increased to $21 \cdot 6 \pm 5.0$ which was $67.5 \%$, thereby showing an increase of 14.4 points or $45.0 \%$ after training. The difference was found highly significant statistically $(t=9.83 ; P<0.001)$.

The mean score was found to be increased during the first follow-up, i.e. after 1 month of training. It was $25 \cdot 5 \pm 5 \cdot 1$ which was $3 \cdot 9$ points more than the previous one. After 3 months, i.e. after 2 more follow-ups, the mean score reached to $27 \cdot 5 \pm 3 \cdot 5$, i.e. $85 \cdot 3 \%$, and the range of score was found to vary from $21 \cdot 0$ to $32 \cdot 0$, i.e. up to $100.00 \%$ in some cases. The differences in mean score in follow-ups increased significantly $(t=3.52 ; P<0.01$ and $t=2.49 ; P<0.05)$, thus showing 
Table 1. Age and sex distribution of selected practitioners

\begin{tabular}{|c|c|c|c|c|}
\hline \multirow[b]{2}{*}{ Age (years) } & \multirow[b]{2}{*}{ Male } & \multirow[b]{2}{*}{ Female } & \multicolumn{2}{|c|}{ Total } \\
\hline & & & No. & $(\%)$ \\
\hline $22-34$ & 7 & 2 & 9 & $45 \cdot 0$ \\
\hline $35-44$ & 3 & 1 & 4 & $20 \cdot 0$ \\
\hline 45 and above & 6 & 1 & 7 & $35 \cdot 0$ \\
\hline Total & $16(80 \cdot 0 \%)$ & $4(20 \cdot 0 \%)$ & 20 & $100 \cdot 00$ \\
\hline
\end{tabular}

Table 2. Pre-training and post-training scores of knowledge of the practitioners regarding leprosy

\begin{tabular}{|c|c|c|c|c|}
\hline Period score $($ total $=32)$ & Range & Mean \pm SD & $(\%)$ & $t$ value $(\mathrm{df}=18)$ \\
\hline Pre-training & $2 \cdot 0-16 \cdot 0$ & $7 \cdot 2 \pm 4 \cdot 1$ & $22 \cdot 5$ & \\
\hline $\begin{array}{l}\text { Post-training } \\
\quad \text { (after 1 week) }\end{array}$ & $9 \cdot 5-29 \cdot 0$ & $21 \cdot 6 \pm 5 \cdot 0$ & $67 \cdot 5$ & $\begin{aligned} t & =9.83 \\
P & <0.001\end{aligned}$ \\
\hline $\begin{array}{l}\text { First follow-up } \\
\text { (after } 1 \text { month) }\end{array}$ & $13 \cdot 0-31 \cdot 5$ & $25 \cdot 5 \pm 5 \cdot 1$ & $79 \cdot 7$ & $\begin{aligned} t & =3.52 \\
P & <0.01\end{aligned}$ \\
\hline $\begin{array}{l}\text { Third follow-up } \\
\text { (after } 3 \text { months) }\end{array}$ & $21 \cdot 0-32 \cdot 0$ & $27 \cdot 5 \pm 3 \cdot 5$ & $85 \cdot 3$ & $\begin{aligned} t & =2.49 \\
P & <0.05\end{aligned}$ \\
\hline
\end{tabular}

that subsequent retraining increased the knowledge of the practitioners still further.

The educational status of practitioners was an important factor in their ability to grasp the training and improve their score. The practitioners with high school or above education scored more than those with little or no education. The age and better retraining score of the practitioners did not affect their scores.

During the 3-month period of post-training assessment 12 leprosy cases attended the Rural Health Training Centre (RHTC). Out of these, 11 cases were referred by trainee practitioners and only 1 by a fellow patient who had learnt about leprosy from one of the practitioners. These leprosy cases were of various clinical types as shown in Table 3.

None of the cases were deformed and a skin smear was positive in the one lepromatous case.

When interviewed, 17 of the practitioners were also willing to be trained similarly in other diseases. 
Table 3. Clinical types of the leprosy cases who attended RHTC during post-training assessment periods

\begin{tabular}{lcccc}
\hline \multicolumn{1}{c}{ Clinical type } & $\begin{array}{c}\text { Reported by } \\
\text { practitioner }\end{array}$ & $\begin{array}{c}\text { Referred by } \\
\text { other persons }\end{array}$ & Total \\
\hline 1 Polyneuritic & 1 & $\mathrm{x} \mathrm{x}$ & 1 \\
2 Maculo Anaesthetic & 3 & $\mathrm{x} \mathrm{x}$ & 3 \\
3 Tuberculoid & 5 & $\mathrm{x} \mathrm{x}$ & 1 \\
4 Borderline & 1 & -1 & 1 \\
5 Lepromatous & 1 & & \\
Total & 11 & & 12 \\
\hline
\end{tabular}

\section{Discussion}

The healer:population ratio is $71: 1000$ for the country ${ }^{1}$ and they constitute the potential reservoir of health manpower, and we should examine the feasibility of harnessing this enormous source of traditional healers to modern and more appropriate medicine. It is estimated that the traditional healers generate primary medical care services 8 times the value of patient's visits offered by the organized Government health system. ${ }^{2}$

The findings of this short-period action research study are encouraging. By subsequent training and retraining the traditional healers' knowledge of leprosy was enhanced (Table 2). From a very poor pre-training level, where none of the practitioners scored above $50 \%$ after 3 months of follow-ups the level was much increased, all of the practitioners scored more than $65 \%$ and a few $100 \%$.

The diffusion of knowledge imparted to the traditional healers and its positive effect on the community is evident from the fact that almost all of the leprosy cases who attended RHTC were referred by the trainees. Most of these cases were new, with early symptoms and were free from deformities. Interrogation revealed that most of these cases had been actively searched for by the practitioner.

\section{References}

${ }^{1}$ Shukla KP. Traditional healers in community health. Varanasi Gomati Krishna Publications, pp. $116 ; 1980$.

2 Alexander CA, Shivaswamy MK. Traditional healers in a region of Mysore. Soc Sci \& Med, 1971; 5: 595 . 